\title{
Personal Divorce Coaching and Its Role in Decision-Making in Divorce
}

\section{Pegotty Cooper and Randall R Cooper}

\begin{abstract}
The role of personal divorce coach assists divorcing clients as they come to grips with the psychological impact precipitated by the breakup of their marriage and with the decision-making required as they end their marriage and plan for their futures. This article uses two scenarios that demonstrate the role of and methods used by a personal divorce coach. Through these practice examples, we will explore how divorce coaching supports effective client decision-making. We will also distinguish divorce coaching from the role of other professionals involved in the divorce process, including attorneys, mediators, therapists and financial consultants.
\end{abstract}

\section{Introduction}

Because of the emotional nature of divorce, the magnitude of change in all aspects of the couple's lives, and the complexity and uncertainty of the legal process, divorcing couples are often poorly prepared to think clearly about the decisions they must make as they grapple with the fear and uncertainty about their future. Moreover, these decisions are being made with a spouse who may not share the same interests and whose thinking is influenced by fears and uncertainty about their own future. The impact of these dynamics may undermine effective and timely decision-making.

The scenarios explored here are typical of the issues, concerns, opportunities and challenges facing most divorcing couples. Through an examination of these practice examples, we will describe the process by which a divorce coach uses relevant theory to evaluate their clients' situations and explain how that assessment leads to choices of intervention strategies and tactics. In addition, the scenarios provide a basis for describing the co-ordination of divorce coaching and other professional services to support the client's decision-making throughout the divorce process. 


\section{Two scenarios as context}

We will start with two scenarios representing different challenges to the process of decisionmaking in divorce. Following these examples, we will look at the theoretical underpinnings relied on by the divorce coaches.

The first scenario focuses on spouses, engaged in a collaborative divorce process, who have failed to reach an agreement. The process is about to be terminated if the clients can't agree on possibly one of the four financial options provided by the financial neutral. The second scenario involves a spouse unable to sign the Marriage Settlement Agreement presented by her attorney because she is under duress. In both examples, we have disguised the identities and details to respect the confidentiality of the clients.

\section{Scenario 1: Greg and Alice and the collaborative divorce process}

Greg and Alice are working professionals. They have significant assets, including a debt-free home and retirement accounts. They have no children. Greg tried to negotiate a divorce settlement agreement with Alice over their kitchen table. That did not go well, and Greg decided to get more help.

The collaborative divorce model for dispute resolution seemed to be a better idea to Greg and Alice. As part of this process, each had an attorney, and they shared a therapist as a collaborative divorce coach/neutral facilitator and a financial planner acting as a neutral financial expert. After months of meetings, with support and advice from the collaborative professionals, the couple had not reached a settlement. Greg wasn't finding the collaborative process helpful. He told his attorney he was going to seek another perspective and was looking for someone who had the same credentials as the collaborative financial planner.

Greg called Rich for an initial consultation, explained the situation and asked the financial planner about his credentials and experience. Rich is a certified financial planner, a certified divorce financial analyst, a court certified family mediator, and a certified divorce coach. Greg believed Rich might have the right type of experience. He explained that he was confused about what to do and asked Rich for help with fashioning a workable settlement agreement.

Greg saw himself as a competent money manager who had been successful in his business. He was surprised that settling their finances turned out to be such a difficult process. Alice wasn't agreeing to anything.

Greg showed up to the first session with Rich with four settlement alternatives; they were complex and involved over 1 million dollars in assets as well as substantial combined marital income. 
Greg was focused on the details of the settlement options and wanted Rich, with his broad range of professional divorce skills and financial expert experience, to comment on the merits of each.

Greg's stress level had significantly increased because the collaborative team told him the day before his meeting with Rich that they were ready to end the process because of a lack of progress. The collaborative group proposed a final meeting. In preparation for that meeting, the collaborative financial neutral had prepared the four settlement alternatives for Greg and Alice to consider. If they could not agree on a settlement the collaborative, process would be terminated. Greg and Alice would have to start over, hiring new attorneys and possibly other professionals. Doing this would stretch out the process, add expense and cause further delays. Greg simply wanted to end the entanglement with his wife and make a clean break.

Rich considered the facts presented by Greg:

- There was a gap between the results he had gotten so far in either approach he had tried for reaching an agreement.

- Greg was annoyed with his wife because of her resistence to being fully employed, which would increase her income and eliminate the need for alimony.

- Four knowledgeable divorce professionals had been working on this problem for months without success.

- Greg was ready to end the entanglement with his wife and make a clean break without a future obligation - without being required to pay alimony.

- He was under greater pressure to reach an agreement with his wife, otherwise the collaborative team would end their efforts.

- His wife was attached to her financial demands and he was trying to find settlement terms that would satisfy her.

The coach began to sort through this information in order to plan his approach.

- He believed that focusing on an analysis and evaluation of the details of the proposed settlement alternatives would probably not be productive.

- Exploring what was acceptable and what was not, and searching for some aspect of the settlement options that could be altered, was unlikely to produce new settlement terms without Alice's co-operation.

- Understanding that an answer to Greg's dilemma would not likely be found in the details of these settlement options, Rich thought it might be useful to explore the client's view of the four options.

- However, because he is also a divorce financial planner, Rich needed to be cautious not to be drawn into the facts of the case and to an analysis of the alternatives. 
Rich asked Greg which of the four settlement options was closest to an ideal settlement; Greg pointed to one of the presentations prepared by the consulting financial planner. Rich asked Greg the reasons for his selection. Greg explained that even though it was not ideal for other reasons, this one did not include alimony. Even though it offered the 'clean break' that Greg had wanted, the option was problematic. Overall, it was unacceptable to him and almost certainly unacceptable to Alice. The problem for the divorce coach was how to proceed from here.

Rich considered how to use his skills as a personal divorce coach to help focus Greg's thinking. The following are among the perspectives of a divorce coach that Rich thought might be relevant in this case:

- Listening deeply, and reflecting back to the client what they are saying, is a very effective tool for uncovering the client's thinking through the words they are using. When hearing their words reflected back, possibly reframed by the coach, clients are often able to take a more objective view of the problem and of potential solutions.

- Asking neutral and open-ended questions encourages the client to think differently and perhaps more creatively.

- Frustration and urgency can easily activate the drive for survival, where every action is perceived as a threat. As a result, the list of possible options becomes drastically narrowed. By creating a sense of safety, simplicity, and familiarity, the coach can shift the client's perspective toward creative problem-solving.

- When a client is stuck in solving a problem, coaches focus on the client's way of thinking about the problem and do not focus on the problem itself.

- By helping the client view the problem differently, the coach helps them to:

$\circ$ uncover a blind spot by shining a light on something they may not have seen before, often an unexamined assumption;

$\circ$ make sense of the facts in a new way - connecting the dots to reveal a different image;

- reframe the situation - to shift their perspective so they can see the facts through a new lens.

- Trust that the client knows what is the best option. Help them recognise the solution by exploring what is in their head (thinking), heart (feeling) or gut (instinct).

The following is an excerpt from the conversation between Greg and Rich.

Coach: Has there ever been an offer on the table which was closer to your ideal settlement?

Client: $\quad$ Early on in the process, I presented what I thought was a very generous offer to my wife. She would receive the house, which was paid for, and had substantial value. Keeping the house, including my share of the equity, in exchange for me not having to 
pay alimony, was a priority for her. In response to my offer, she insisted she needed an additional $\$ 25,000$ for urgent repairs.

Coach: It sounds like early on there was an option with something worthwhile for both of you. What happened?

Client: I thought it was a good offer and couldn't understand why I should have to also give my wife another $\$ 25,000$. I don’t think she realised how generous I was being to give her the whole debt-free house. She is capable of earning money for those repairs, but she always finds a reason not to get back into her career. So I rejected her counter-offer and went back to the drawing board with the collaborative team.

Coach: $\quad$ So, let me see if I understand what you are telling me. You created your ideal offer and then she asked for more money to repair the house, and that was when it fell apart.

Client: (Client leaned forward, tossed his head and said in louder and in an annoyed tone) "It was the principle of the thing! I wasn't going to bend any more to her demands. After all, I had given her the house which represented a good chunk of money, and I didn't want her to think she could keep upping the demands."

The reason for the impasse was becoming clearer - namely, the client's thinking. Greg had made one of the six biggest mistakes someone can make in divorce: taking the 'my way or the highway' approach to negotiating. Digging in one's heels, strongly resisting alternatives, maintaining an emotional attachment to a position, all can have negative consequences for the decision-making process and prolong the effort. In this case, fees for the collaborative professionals far exceeded the amount of money Alice had demanded for house repairs.

Coach: $\quad$ Let me be clear about what you are saying. You created your ideal offer, and your wife accepted the offer. You then rejected your own ideal offer when she asked for money for house repairs.

Client: (Client was silent for about 15 seconds, and then the expression on his face turned into one of panic). "I can't believe I did that. I wonder if I can revive that offer! It would mean we could wrap this up and settle this whole negotiation."

Coach: (Anticipating future obstacles for the client's situation, the coach offered the following.) "You don't have to answer my next question right now. As you make this offer to your wife again, what would happen if your wife made another request for more money? (silence). How much would it be worth to you at this point to agree to any counteroffer from her and settle the whole matter? It is just something to think about."

If Rich had simply pointed out Greg's mistake, digging in his heels about a perceived principle, it would most likely be seen by Greg as a challenge. As he had demonstrated in rejecting Alice's counter- 
offer, this observation would be resisted. Rich understood that a divorce coach can better help his client by helping him discover his own mistake.

Understandably, Greg (as clients often do in a similar situation) had difficulty seeing this type of mistake. Rich's strategy was to 'shine a light' on what had occurred and to encourage Greg to experience a new way of looking at the impasse. In this way, Greg came to see how he had ("on principle") rejected his own best offer. By helping Greg see the events through a different lens, it caused a shift in Greg's thinking about the choices that lay before him.

Recognising when someone digs in their heels is a relatively straightforward process. The challenge is to intervene in a way that helps shift the client's mindset. Using logical analysis or attempting to argue with or persuade Greg would have had little impact. It's not probable that he would be able to reason away his client's attachment to a principle. Instead, Rich shifted the perspective to allow Greg to see his behaviour and the consequences differently.

Greg returned to the negotiations with Alice, hopeful of resurrecting his offer. He was successful. Alice accepted Greg's original settlement offer along with the additional money.

The financial neutral focuses on the numbers, working on the details at the problem-solving level - exactly what he was trained to do. When confronted by the client's resistance, he rearranges the details to provide a different solution. The attorney is focused on the client's legal rights and responsibilities. The neutral facilitator helps the parties work collaboratively, identify the common concerns and develop the efforts to address those concerns. The personal divorce coach is outside of the collaborative process and has a different lens through which he or she can help the client to see the problem in a different way leading to a new awareness.

\section{Scenario 2: Client is unable to sign the agreement except under duress}

Lillian had initiated the divorce; the relationship with her husband had been very unsatisfying for many years. She and her husband are employed. They have agreed to co-parent their child. Through mediation, Lillian and her husband had come to an agreement. Getting to this point had been difficult; she had been emotionally distraught during the final mediation session. When her attorney presented the settlement agreement, she couldn't sign it. She was frozen. She was crying and angry and insisted that the mediator, her attorney and her husband were trying to force her into an agreement. The mediator, having determined Lillian might be acting under duress, decided not to ask her to sign the agreement and ended the mediation session. In her lawyer's experience, this was not the first time Lillian had sunk into a dysfunctional emotional state. 
The lawyer thought Lillian might benefit from talking with a divorce coach. Lillian was open to the recommendation and scheduled an initial consultation with Stephanie. Based on the 45-minute consultation the coach concluded the following:

- Lillian is under a lot of pressure to sign this agreement, but she does not feel as though it was HER agreement.

- She wanted this divorce, but now that the goal is near, she realises something has happened that undermines her confidence in being able to survive on her own.

- She is worried about losing her job, about having enough for retirement, about being able to care for the house, and about a dozen other things that could happen.

- She feels paralyzed and unable to make any decisions.

- Lillian is overwhelmed by the document - the Marriage Settlement Agreement - and fears what might happen to her in the future.

The coach reflects on the situation and considers how she can use her knowledge, beliefs, and skills to help Lillian to see this situation differently, to get unfrozen, and be able to move forward. Lillian felt threatened by the uncertainty of life after divorce. Her constant focus on exploring the negative occurrences that might possibly happen some time in the future point to Lillian's desire to minimise or conquer these threats. David Rock (2008) contends that two impulses drive human behaviour: minimising threats and maximising reward. Rock's SCARF MODEL describes five common factors that activate the threat and reward responses:

Status - relative importance to others;

Certainty - being able to predict the future;

Autonomy - a sense of control over events;

Relatedness - a sense of safety with others; and

Fairness - the perception of fair exchanges between people.

Lillian's repeated concerns and worries point to her having little confidence in what might happen in the future; she imagines a series of disastrous outcomes. Her lack of certainty is likely activating a strong threat response. As a result, she freezes and cannot move forward until she feels some degree of certainty and confidence.

The first step in helping Lillian address the threat response is to create a calm, safe, nonjudgmental environment to help calm her emotional responses. This can be accomplished in several ways:

- Breaking big things down into smaller pieces: Focusing on one small piece at a time makes it easier to process and understand the terms of the agreement. 
- Recognising that each comment a client makes may hold the key to helping her shift her perspective, we seek to turn her thinking towards what is working. We look for opportunities to explore ways to help her move away from uncertainty in order to help her regain a measure of control.

- By shining a light on the clients' anxieties, the coach helps the client identify and acknowledge her underlying assumptions. The client and coach then examine the assumptions to determine whether they are accurate and realistic.

- As human beings, we want to be heard, to be respected and to have a say. This is often more important because it re-establishes some connection in our human social experience.

- Human beings have the innate strength and capacity for utilising resources and finding solutions. Sometimes, current circumstances can impair their ability to access their strengths and resources.

Based on her assessment of Lillian's situation, the coach asks herself: "How can I help Lillian shift her focus from being overwhelmed by the enormity of the entire situation to seeing the smaller component parts? Dealing with one piece at a time could alleviate her fear and enable her to make thoughtful decisions."

During the coaching session, the coach determines that the initial step is to shine a light on each detail of the agreement as a means of helping the client discover that her fears about the agreement may not be accurate or realistic.

Coach: I know you have some concerns that are making it difficult for you to sign the agreement. You are not alone here. These agreements can be tedious to review by yourself because you must go through them and look at every detail.

Client: I am pretty sure my attorney did this with me, but she went so fast I couldn't follow most of what she was saying.

Coach: $\quad$ I would like to help you do this and understand each of your concerns.

Client: $\quad$ There are so many unknowns for me. What if I lose my job? I don't know if I will have enough money for retirement. I am afraid of losing my husband's income in all of this and don't know if I will have enough. Now that the divorce is becoming real, I am terrified about the future and can't bring myself to sign the agreement. I don't know what to do!

Coach: (The client is focused on some unknowable future event that then becomes an obstacle to moving forward.) Let's look at that for a minute. Do you have some indication that you might lose your job?

Client: Well, no, but our contract is coming up again in the next couple of years, and you never know if the funding will be approved.

Coach: If you have ever lost a job before, how have you handled it? 
Client: Well, my resume is so out of date and doesn't include the last five years of work.

Coach: How would it be if after your divorce is settled, I help you get organised and ready with your resume in case you need it in the future?

Client: $\quad$ I would like to work with you on that after this is all done. I can use all the help I can get!

Coach: Let's start with the agreement. I suggest we start at the beginning and together we will walk through it. We can stop any time you want. How does that sound to you? (The client nods her head in agreement.) Let's look at the first provision.

Client: $\quad$ That is a perfect example. It's written in such legalese that I don't understand it at all and it drives me crazy.

Coach: Let's write down these concerns on a separate piece of paper. Can you state this as a question? What would your question be?

To help the client shift her attention and focus to calm her anxiety, the coach asks the client to pick up a writing instrument and note her concern, reformulated as a question. This simple act causes her to stop, think of the words she needs to convert her concern into a question. She is accessing her resources and strengths instead of reacting emotionally. In this way, the coach is separating Lillian's emotions from a fact-based, problem-solving approach.

Client: $\quad$ My question regarding this would be, what does this first provision mean to me without all the legalese?

Coach: $\quad$ OK, write that down. Next to it write the word lawyer, because getting clarification, in plain language, would need to come from your lawyer.

Coach: Now let's move onto the next provision. This one is talking about money. It says here that you two are to divide the brokerage account $50 \%$ for each of you.

Client: $\quad$ I didn't understand it that way. We always talked about a dollar amount in cash that I would receive from that account.

Coach: $\quad$ So how would you write that as a question on your list of questions?

Client: Why can't this say a dollar amount that I receive from this account as we have agreed?

Coach: If you can recall the dollar amount that was discussed, write that figure. And right next to it write the word "lawyer". When you are finished, let's go to the next provision.

Client: $\quad$ It says here that we are supposed to split the 401(k) in half, and I know that there are tax issues in doing that. I think this will make some tax problems for me. And I don't understand what this means: "qualified domestic relations order".

Coach: Let's write those questions down on your list.

Client: What are my tax consequences for dividing the $401(\mathrm{k})$ ? What is a qualified domestic relations order? And who is going to do that? 
Coach: Great questions. That needs to be explained more clearly for you. And next to those questions write the words "lawyer" and "financial expert". You are getting good at framing the questions you want to ask. What are you noticing as you go through this agreement one item at a time?

[Acknowledging the client and noticing when a client makes the smallest shift toward taking control of matters helps to build their confidence and self-esteem.]

Client: I am seeing that it is a lot less intimidating and having you sitting here helping me to focus on each of these paragraphs is very helpful. And I appreciate that you are not making me feel stupid or incompetent in this exercise!

Coach: Lillian, I can tell by the way you are wording your questions that you have a lot of knowledge about these things. And I have noticed a different level of confidence in the way you are asking your questions.

So it went, through the entire marriage settlement agreement.

Following this review, Lillian took the agreement to her attorney and a financial expert. As a result, some things were clarified, one provision was corrected because there was an error, and another aspect was improved upon from her perspective. In the end, Lillian felt that she had done all that she could do to make a workable agreement. It was the best agreement she could make. She was then able to sign the agreement.

The distinction between the divorce coach and other professionals is the mindset they bring. Lawyers are advocates, they are advisors. They provide information and advice, perhaps even to the point of telling the client what they should or should not agree to. Financial planners offer analysis - collecting and evaluating data and presenting options for consideration. They are not focused on the decisionmaking process. Therapists focus on addressing patterns of behaviour that may be interfering with the client's ability to navigate the activities of life. The mediator is a conflict solver and helps the divorcing couple work together through mutual problem solving to arrive at a solution. A coach, in this case, helps the client, as an individual, to shift perspective to allow the agreement to become the client's agreement, dissolving the perception of a process-developed agreement decided for the client.

\section{Divorce coaching and decision-making in divorce}

Divorce is a process that can overwhelm your life. Decisions made during this period can result in serious mistakes that can have long-term consequences for everyone involved. Everyone is affected including the professionals who support the divorcing client! The divorce process can also allow the 
opportunity for the client to make decisions consistent with who they are when they are at their best, connected to their values, and supporting a vision for their future.

There are many ways in which decision-making can be derailed during the divorce process, and we have found that many of the mistakes people make in their decision-making can be traced back to six recurring mindset mistakes that are at the root of many of the subsequent legal and financial mistakes (Cooper and Cooper, 2014). We have explored the first two in the two scenarios we just shared:

1. 'My way or the highway' position. The story of Greg and Alice illustrates the perils of this mindset.

2. Wanting guarantees and certainty. Lillian's story shows how this mindset can produce paralysis from wanting enough guarantees in the resolution to ease all uncertainty.

The other four mistakes are common to many divorcing spouses and relatively easy to recognise. The challenge for divorce coaches is to help clients shift their mindset to see new options and obtain different results. The four mistakes are:

3. Throwing in the towel. Making visceral emotional decisions to give up may relieve the client's exhaustion and stress but can create long-term consequences which are more difficult to address after the fact.

4. Abdicating decision-making. Both parties are forgetting that they are both the decisionmakers in the process. This manifests itself in several ways - often not being clear about which outcomes are most important to them in the process, or by relinquishing decision-making to another party, often the attorney or the spouse in the mediation process.

5. Betting the farm on another relationship. Before the divorce is final, one of the parties finds another relationship and bets everything on that relationship when choosing to walk away from what they may have had rights to in the current divorce settlement.

6. Relying on too few experts. One or both parties limit their use of other experts who can help them to see the whole picture or fill in missing information or a missing perspective on a specific position one might be taking, thereby limiting effective decision-making.

Here is a framework for positively impacting the decision-making process when encountering one of these mindsets :

1. Listen to the client: pay attention to the client wishes. Do not challenge, second-guess or judge. Help the client remain calm, focused and lower the wall of resistance.

2. Focus on the practical aspects of the issues, such as, how will this work? Who will be involved? When will this happen, and what can you do to make sure that the plan works for you? 
3. You may acknowledge the client's emotions, but the coach explores the issues on the basis of facts, rather than the client's emotionally charged reactions. Doing so helps the client distance herself from the first story (anxiety, confusion, distress) and focus on the new story (calm, focused acceptance).

4. Encourage the client to identify who can help them examine their assumptions (for example, experts) and assist her to organise his or her thoughts and questions so as to maximise the benefit from any consultation.

5. Help the client to rehearse conversations with others involved such as, their spouse, attorney, financial expert, children, and any others who are seen as essential to the decisionmaking and who may be affected by this outcome.

Divorce coaching is a process that borrows the concepts from many sources:

- The working of the mind and the brain and the effects of the fast-responding amygdala designed for survival on thinking, communication, problem-solving and decision-making (Heath and Heath, 2013; Rock, 2006; Siegel, 2010, 2016; Stone et al, 2001).

- The cycle of change, the process of transition and the resulting uncertainty can provide both a hazard and an opportunity for the client (Bridges, 2001; Wolfelt, 2008).

- Coaching focuses on encouraging the client to recognise behaviours that may stimulate negative reactions, including defensiveness, then helping the client difuse the potential impact of those behaviours (Noble 2011, 2014; Lenski, 2014).

- High conflict personalities often emerge during divorce; these may involve fuzzy thinking and confrontational methods of communication (Eddy, 2016); and

- Shifting the narrative from the story of divorce to a story of creating a new chapter in their life, a narrative in which divorce doesn't define the client but is seen as part of a process of awareness and transformation (Drake, 2018).

Divorce coaches work with clients in the nitty-gritty decision-making of everyday life while keeping in mind the client's bigger picture issues. As a thinking partner, divorce coaches help the clients prepare themselves for long-lasting change with new and broader perspectives which will serve them as they move into their new roles.

Divorce itself doesn't have to be difficult. The problem generally isn't the problem and focusing on the problem distracts from focusing on the real issues - the thinking about the problem. As Captain Jack, from the movie Pirates of the Caribbean, reminds us: "It isn't the problem that is the problem, it is your attitude [thinking] about the problem that is the problem". It is all the other personal dynamics such as conflict, emotional decision-making, expectations, blind spots, power imbalances, high-conflict personalities, all of which have an impact on decision-making, communication, and the ability to get 
organised, that make divorce challenging for everyone involved. These dynamics have a big impact on the process of divorce and prioritising what is needed for the next chapter.

\section{Consideration for future development}

Divorce coaching is an emerging profession. There is now a formalisation of best practices, ways to assess divorce coaching competencies, ethics and case studies. Personal divorce coaching continues to evolve.

Globalisation and accommodation to various cultures and languages are being promulgated by certified divorce doaches as they see the potential for integrating the divorce coaching practice into their country, jurisdiction, or religious community.

As we think about what is next, we will benefit from bringing others into the conversation - the clients and other professionals. We need to ask: "What does the future need from all of us?" and "How do we as professionals all work together, instead of in parallel?" 


\section{References}

Arbinger Institute (2015) Anatomy of Peace: Resolving the Heart of Conflict. Oakland, CA. BerrettKoehler.

Bridges, W. (2001) The Way of Transition: Embracing Life's Most Difficult Moments. Cambridge, MA. Perseus Press

Cooper, P. and Cooper R. (2014) Divorce: Overcome the Overwhelm and Avoid the Six Biggest Mistakes, Tampa, Fl. Divorce Coaching Inc.

Drake, D.B. (2018) Narrative Coaching: The Definitive Guide to Bringing New Stories to Life. Petaluma, CA. CNC Press.

Eddy, B. (2016) High Conflict People in Legal Disputes. Scottsdale, AZ. Unhooked Books.

Heath, D. and Heath, C. (2013) Decisive: How to Make Better Choices in Life and at Work. New York, NY. Crown Publishing.

Lenski, T. (2014) The Conflict Pivot: Turning Conflict into Peace of Mind. Peterborough, NH. MyriaccordMedia

Noble, C. (2011) Conflict Management Coaching: The CINERGYTM Model, CINERGYTM Coaching.

Noble, C. (2014) Conflict Mastery, Questions to Guide You. CINERGYTM Coaching. c

Rock, D. (2006) Quiet Leadership. New York, NY. Harper Collins.

Siegel, D.J. (2010) Mindsight: The New Science of Personal Transformation. New York, NY. Bantam Books

Siegel, D.J. (2016) Mind: A Journey into the Heart of Being Human. New York, NY. W.W. Norton \& Co. Stone, D., Patton, B., Heen, S., and Fisher, R. (2001) Difficult Conversations: How to Discuss What Matters Most. New York, NY. Penguin Books.

Wolfelt, A.(2008) Transcending Divorce: Ten Essential Touchstones for Finding Hope and Healing in Your Heart. Ft. Collins, CO. Companion.

Randall R. Cooper, MBA, Certified Financial Planner (CFP®), and Certified Divorce Financial Analyst $(\mathrm{CDFA} \cap)$

Supreme Court of Florida Certified Family Mediator since 2005.

Pegotty Cooper, MBA, Certified Coach since 2002.

Co-Founders CDC Certified Divorce Coach ${ }^{\circledR}$ Certification in January 2011.

Co-Authors: Divorce: Overcome the Overwhelm and Avoid the 6 Biggest Mistakes, 2014, and

Divorce: Taking the High Road, 2016.

website: www.certifieddivorcecoach.com

Phone: 813-455-1134 
Pegotty Cooper, CDC Certified Divorce Coach ${ }^{\circledR}, \mathrm{MBA}$

Co-Founder CDC Certified Divorce Coach ${ }^{\circledR}$ Certification

Co-Author: Divorce: Overcome the Overwhelm and Avoid the 6 Biggest Mistakes and

Divorce: Taking the High RoadBiographies

Randall R. Cooper, MBA, CFP®, CDFA $\AA$

Supreme Court of Florida Certified Family Mediator.

Pegotty Cooper, CDC Certified Divorce Coach ${ }^{\circledR}, \mathrm{MBA}$

Co-Founders CDC Certified Divorce Coach® Certification

Co-Authors: Divorce: Overcome the Overwhelm and Avoid the 6 Biggest Mistakes and

Divorce: Taking the High Road 